\title{
Hábito alimentar de escolares adolescentes de um município do oeste do Paraná
}

\author{
Food habits of adolescent students from a \\ municipality in western Paraná, Brazil
}

Marcia Cristina DALLA COSTA ${ }^{1}$

LUiz CORDONI JÚNIOR²

Tiemi MATSUO ${ }^{3}$

\section{Objetivo}

Este estudo objetivou identificar o padrão de consumo alimentar de 2562 escolares de 14 a 19 anos das escolas urbanas, públicas e particulares, do município de Toledo, Paraná, bem como os fatores associados à classe econômica e ao sexo.

\section{Métodos}

Para caracterizar o consumo alimentar utilizou-se Questionário de Freqüência de Consumo Alimentar validado. A análise estatística foi realizada seguindo os grupos da pirâmide alimentar, e as associações das variáveis foram realizadas pelo teste Qui-quadrado com nível de significância de 5\%.

\section{Resultados}

Os alimentos que apresentaram maior consumo em cada grupo foram: pão e arroz, alface e tomate, banana e laranja, leite integral e desnatado, carne de gado e frango, feijão, margarina e maionese, açúcar e balas/doces. A associação da freqüência de consumo com a renda familiar foi significante entre os mais pobres para os grupos dos pães, cereais, raízes e tubérculos, das leguminosas e dos óleos e gorduras. Entre os mais ricos encontram-se os grupos das hortaliças, das frutas, dos leites e produtos lácteos. Quanto ao sexo, as meninas consomem mais alimentos dos grupos das hortaliças e dos açúcares e doces, já entre os meninos prevalece o consumo de leite, leguminosas, óleos e gorduras.

\section{Conclusão}

Esses resultados mostram diferença de consumo entre os sexos e sugerem que a renda famíliar associa-se ao consumo alimentar dos escolares.

Termos de indexação: adolescente; avaliação nutricional; hábitos alimentares; pirâmide alimentar.

\footnotetext{
$\overline{1}$ Universidade Estadual do Oeste do Paraná, Curso de Farmácia. R. Universitária, 1619, Jd. Universitário, 85814-110, Cascavel, PR, Brasil. Correspondência para/Correspondence to: M.C. DALLA COSTA. E-mail: <marciacdc@uol.com.br>.

2 Universidade Estadual de Londrina, Departamento de Saúde Coletiva. Londrina, PR, Brasil.

3 Universidade Estadual de Londrina, Departamento de Estatística. Londrina, PR, Brasil.
} 
462 | M.C. DALLA COSTA et al.

\section{A B S T R A C T}

\section{Objective}

The objective of this study was to identify the food intake patterns of 2562 students aging from 14 to 19 years from public and private schools of the municipality of Toledo, Paraná, Brazil. Associations between intake patterns and gender and intake patterns and social class were also investigated.

\section{Methods}

A validated food frequency questionnaire was used to characterize food intake. Statistical analysis was based on the food guide pyramid and the variables associated with the chi-square test, using a significance level set at $5 \%$.

\section{Results}

The foods with highest intakes were: bread and rice, lettuce and tomato, banana and orange, whole milk and skim milk, beef and poultry, beans, margarine and mayonnaise, sugar and candies/sweets. The association between intake frequency and family income was significant among the poorest for the following groups: breads, cereals, nuts and seeds, legumes and oils and fats. Among the wealthiest, the groups were: vegetables, fruits, milks and dairy. Regarding gender, girls consume more vegetables and sweets and boys consume more milk, legumes, oils and fats.

\section{Conclusion}

These results show that there is a difference in intakes between genders and suggest that family income is associated with food intake among students.

Index terms: adolescent; nutrition assessment; food habits; food pyramid.

\section{N T R O D U ÇÃ O}

Pesquisas nacionais realizadas nas últimas três décadas, no Brasil, vêm demonstrando um decréscimo na prevalência da desnutrição infantil e aumento da obesidade em adultos, principalmente em mulheres, caracterizando um período de transição nutricional ${ }^{1,2}$. Monteiro et al. ${ }^{3}$ comentam que em cada país e região do mundo a transição nutricional ocorrida no século XX apresentou-se de modo singular, mas elementos comuns convergem para uma dieta rica em gorduras (principalmente de origem animal), açúcares e outros alimentos refinados, e reduzida em carboidratos complexos e fibras.

A obesidade é o desequilíbrio entre o consumo alimentar e o gasto energético ${ }^{4}$. Está associada ao sedentarismo e à inadequação alimentar e é considerada um dos principais determinantes da alta prevalência de doenças crônicas como as cardiovasculares, a hipertensão e o diabetes mellitus tipo $2^{5}$.

Ao avaliar as mudanças ocorridas em três inquéritos nacionais, as Pesquisas de Orçamento
Familiar (POF), das décadas de 60 e 80, e o Estudo Nacional da Despesa Familiar (ENDEF), de 1974/75, Mondini \& Monteiro ${ }^{6}$ observaram: a redução no consumo de cereais e derivados, feijão, raízes e tubérculos, principalmente da década de 1970 para a de 1980; o aumento contínuo no consumo de ovos, leite e derivados; a substituição da banha, bacon e manteiga por óleos vegetais e margarina; e o aumento no consumo de carnes.

Monteiro et al. $^{3}$, ao analisarem as mudanças na composição orçamentária familiar ocorridas entre as POF de 1988 e 1996 no conjunto das áreas metropolitanas das regiões do Centro-Sul, consideraram como mais importantes o aumento relativo na oferta de carnes e a redução na participação de óleos e gorduras vegetais. Encontraram, também, a redução de raízes e tubérculos em menor grau, e a estagnação de cereais, verduras, legumes, frutas e sucos naturais. Os dados da POF 2002/03 mostram que o brasileiro vem reduzindo o consumo de alimentos tradicionais, como arroz, feijão, batata, pão, açúcar e leite de vaca pasteurizado, e aumentando o consumo de alimentos preparados $^{7}$. 
Segundo Sichieri", "os hábitos alimentares se modificam, e muito rapidamente. A mídia os constrói e os substitui". Essa influência pode ser verificada em estudo desenvolvido no Brasil com adolescentes de classe econômica baixa, o qual mostrou que a propaganda recebe lugar de destaque como fonte de informação sobre questões nutricionais, entre os adolescentes ${ }^{8,9}$.

A influência da renda aparece menos expressiva sobre o consumo alimentar da população, sendo específica a determinados tipos de alimentos ${ }^{10}$. Entretanto, pesquisa desenvolvida em 1994, com 535 famílias de Campinas, mostrou que o consumo é fortemente determinado pelo padrão econômico da família, sendo a renda um fator importante na determinação do consumo alimentar da população. Com o aumento da renda familiar, diminuiu o consumo de arroz e feijão e aumentou o consumo de carne bovina e frango, com menor expressão para o último ${ }^{11}$. Os resultados reforçam os obtidos pelo ENDEF, realizado na década de 1970, que indicam que quanto maior o poder aquisitivo familiar, menor a proporção de famílias cuja ingestão alimentar não satisfaz aos requisitos energéticos do conjunto de seus membros ${ }^{12}$.

Uma vez que dados de consumo alimentar permitem observar as características e o hábito alimentar de uma população, que abordagens que levem em conta os alimentos, e não só os nutrientes, são mais facilmente transformadas em práticas de saúde pública ${ }^{4}$ e, ainda, que as conseqüências dessas práticas alimentares são refletidas no perfil nutricional das populações, o objetivo deste estudo foi caracterizar o padrão de consumo alimentar de escolares adolescentes de um município do Oeste do Paraná, bem como verificar a sua associação com a classe econômica e o sexo.

\section{M É T O D O S}

O estudo transversal foi desenvolvido no município de Toledo, PR, com escolares de 14 a 19 anos matriculados no ensino médio. À época do estudo o município contava com 10 escolas públicas e 4 particulares, totalizando 5.349 escolares matriculados no ensino médio, dos quais, 3.039 alunos freqüentavam o período diurno, da área urbana, sendo estes objeto do estudo. Destes, 2.608 escolares estavam matriculados em escolas públicas e 431 em escolas particulares, dos quais foram excluídos os transferidos para o período noturno ou para outros colégios, as gestantes e aqueles com algum membro engessado, restando 2.717 estudantes como integrantes da pesquisa.

Utilizou-se questionário pré-testado para levantamento dos dados pessoais e biológicos. Para a situação econômica, adotou-se o critério de Classificação Econômica Brasil da Associação Nacional de Empresas de Pesquisa (ANEP) ${ }^{13}$, cujas classes econômicas (da maior renda familiar para a menor) foram agrupadas em: $A(A 1+A 2), B$ $(B 1+B 2), C$ e $D+E$.

Para levantamento do hábito alimentar foi utilizado o Questionário Semiquantitativo de Freqüência Alimentar validado, proposto por Sichieri \& Everhart ${ }^{14}$, com adaptações de acordo com os hábitos alimentares da região e a idade dos escolares, totalizando 84 alimentos. A coleta de dados foi realizada nas escolas, no período de abril a junho de 2003, sendo o questionário preenchido pelo aluno em sala de aula com acompanhamento dos auxiliares de pesquisa e da pesquisadora, em sessões de 50 minutos. As freqüências de consumo alimentar foram separadas em 8 opções para o preenchimento do questionário, a saber: mais de três vezes por dia, de duas a três vezes por dia, uma vez por dia, de cinco a seis vezes por semana, de duas a quatro vezes por semana, uma vez por semana, de uma a três vezes por mês, nunca ou quase nunca, e condensadas em 4 opções para análise, distribuídas em diário, semanal, mensal e anual/nunca.

A caracterização do padrão de consumo alimentar foi realizada agrupando-se os 5 alimentos mais consumidos pelos escolares, de acordo com os 8 grupos da pirâmide alimentar adaptada por Philippi et al. ${ }^{15}$, ou seja: Grupo 1: pães, cereais, raízes e tubérculos; Grupo 2: horta- 
liças; Grupo 3: frutas; Grupo 4: leite e produtos lácteos; Grupo 5: carnes e ovos; Grupo 6: leguminosas e oleaginosas; Grupo 7: óleos e gorduras; Grupo 8: açúcares e doces.

A equipe de campo, composta por três nutricionistas e seis acadêmicas do Curso de Nutrição, foi previamente capacitada para aplicação do questionário. O pré-teste foi desenvolvido em uma turma do ensino médio, período noturno, de escola pública do município, cumprindo todas as etapas da pesquisa.

As informações foram armazenados em um banco de dados elaborado no programa Epi info v.6.0, e a análise estatística foi realizada no programa SAS (Statistical Analysis System). As associações das variáveis socioeconômicas e de consumo alimentar, foram realizadas usando o teste Qui-quadrado de Pearson com nível de significância de 5,0\%.

O projeto foi aprovado pelo Comitê de Ética em Pesquisa da Universidade Estadual de Londrina, parecer CEP 019, de 2003.

\section{RES U LTA D OS}

Dos 2.717 escolares adolescentes selecionados para a pesquisa, participaram 2.562, representando uma perda de 5,7\% (155). Destes, 49 não participaram por recusa, 99 por estarem ausentes nos dias da pesquisa e 7 pelo não consentimento dos pais. A idade média observada foi de 16 (desvio-padrão - DP= 1 ano), a mediana de 16 anos, e 52,7\% tinham entre 14 e 15 anos, sendo $55,5 \%$ do sexo feminino. A classe econômica familiar prevalente, no caso dos adolescentes de escolas públicas, foi a classe C $(44,8 \%)$ e nas escolas particulares, B (49,5\%).

Ao analisar a freqüência das refeições diárias relatadas, o almoço foi o mais prevalente $(98,4 \%)$, seguido do jantar $(83,6 \%)$ e do café da manhã $(66,5 \%)$. No que se refere aos lanches, a maior freqüência foi observada para o lanche da tarde $(73,0 \%)$. Quanto ao sexo, os meninos realizavam as refeições principais com maior freqüência (café da manhã $p<0,0001$; almoço $p=0,0012$; jantar $p<0,0001)$ e, as meninas, 0 lanche da tarde $(p<0,0001)$. Independentemente da classe econômica existiu um predomínio para 4 ou mais refeições/dia, sendo estas realizadas por $55,6 \%$ da população de estudo $(p=0,0159)$.

A freqüência de consumo diário e semanal dos escolares e a distribuição de acordo com os grupos da pirâmide alimentar e suas associações com a classe econômica e o sexo estão apresentadas na Tabela 1, sendo estas consideradas como padrão de consumo alimentar dos escolares. Os alimentos que apresentaram freqüência de consumo mensal, anual ou nunca, foram considerados não integrantes do hábito alimentar dos escolares.

Do grupo dos pães, cereais, raízes e tubérculos, os alimentos mais consumidos, diariamente, foram o pão e o arroz; e, semanalmente, o macarrão, a batata e a mandioca. Deste grupo, entre os alimentos que não chegavam a ser consumidos mensalmente estão a polenta (42,2\%) e o milho $(36,4 \%)$, demonstrando não fazerem parte do hábito alimentar destes escolares. Para a análise das associações desse grupo utilizou-se a freqüência de consumo diário, cuja associação com as classes econômicas mostrou significância estatística para os escolares da classe $\mathrm{D}+\mathrm{E}$, em todos os alimentos.

Desse grupo, apenas o consumo de arroz não esteve associado ao sexo. Para os demais alimentos, os meninos apresentaram maior freqüência de consumo que as meninas de macarrão, pão, pão doce, polenta, mandioca, milho e batata. O biscoito salgado foi mais consumido pelas meninas.

No grupo das hortaliças, com exceção do alho $(46,3 \%)$ e da cebola (37,0\%), que são utilizados também como tempero diariamente, as hortaliças mais consumidas em ordem decrescente de consumo foram alface, tomate, repolho, cenoura e pepino. Entre as hortaliças não eram consumidas a chicória $(78,6 \%)$, o quiabo $(72,7 \%)$, a abóbora $(72,2 \%)$, a vagem $(66,7 \%)$ e a abobrinha (62,5\%). Ao analisar as freqüências de consumo (diário + semanal) deste grupo, associadas às classes econômicas, encontrou-se significância estatística entre as seguintes horta- 
liças, mais consumidas pela classe A: alface, couve-folha, chicória, pepino, chuchu, vagem, cebola, abobrinha, cenoura, abóbora, beterraba e couve-flor. Na classe D+E destacaram-se repolho, tomate, pimentão e alho.
Quanto ao sexo, as meninas apresentaram maior consumo do que os meninos para repolho, pepino, cebola, beterraba, couve-flor e alho.

No grupo das frutas, as mais consumidas foram a laranja e a banana, seguidas da maçã,

Tabela 1. Distribuição da freqüência de consumo alimentar de escolares, de acordo com o grupo alimentar, tipos de alimentos mais consumidos e associação do consumo com a classe econômica e gênero. Toledo, PR, 2003.

\begin{tabular}{|c|c|c|c|c|c|c|}
\hline \multirow{2}{*}{ Grupos } & \multirow{2}{*}{ Alimentos } & \multicolumn{2}{|c|}{ Freqüência (\%) } & \multirow{2}{*}{ Total (n) } & \multicolumn{2}{|c|}{ Valor de $p$ das variáveis } \\
\hline & & Diário & Semanal & & Classe econômica & Gênero \\
\hline \multirow{5}{*}{1} & Pão & 80,0 & 15,8 & 2560 & $0,0081^{*}$ & $0,0010^{*}$ \\
\hline & Arroz & 79,4 & 19,2 & 2562 & $<0,0001^{*}$ & 0,1357 \\
\hline & Macarrão & 24,0 & 63,4 & 2562 & $<0,0001^{\star}$ & 0,0021 * \\
\hline & Batata & 19,4 & 60,7 & 2562 & $<0,0001^{*}$ & $0,0064^{*}$ \\
\hline & Mandioca & 15,7 & 43,4 & 2558 & $<0,0001^{*}$ & $<0,0001$ * \\
\hline \multirow{5}{*}{2} & Alface & 31,7 & 42,2 & 2559 & $<0,0001 *$ & 0,0929 \\
\hline & Repolho & 19,2 & 42,2 & 2561 & $0,0004^{*}$ & $<0,0001$ * \\
\hline & Tomate & 28,2 & 45,4 & 2561 & $0,0010^{*}$ & 0,3661 \\
\hline & Pepino & 11,1 & 31,2 & 2562 & $<0,0001^{*}$ & $0,0004 *$ \\
\hline & Cenoura & 16,7 & 35,0 & 2560 & $<0,0001^{*}$ & 0,1986 \\
\hline \multirow{5}{*}{3} & Laranja & 28,7 & 44,7 & 2561 & $<0,0001^{*}$ & $0,0079 *$ \\
\hline & Banana & 29,3 & 44,2 & 2562 & 0,0869 & $0,0064 *$ \\
\hline & Mamão & 14,6 & 32,1 & 2562 & $<0,0001^{*}$ & 0,8538 \\
\hline & Maçã & 22,5 & 42,1 & 2561 & $0,0005^{*}$ & 0,2689 \\
\hline & Limão & 18,6 & 38,2 & 2562 & $<0,0001^{*}$ & $0,0012^{*}$ \\
\hline \multirow{5}{*}{4} & Leite integral & 45,9 & 18,3 & 2559 & $0,0211^{*}$ & $<0,0001$ * \\
\hline & Leite desnatado & 27,3 & 16,3 & 2558 & $<0,0001^{*}$ & 0,5942 \\
\hline & logurte & 15,6 & 39,2 & 2559 & $<0,0001^{*}$ & 0,0031 * \\
\hline & Queijo & 26,2 & 37,3 & 2560 & $<0,0001^{*}$ & $0,0144^{*}$ \\
\hline & Requeijão & 8,4 & 16,8 & 2559 & $<0,0001^{*}$ & 0,7236 \\
\hline \multirow{5}{*}{5} & Frango & 20,0 & 68,1 & 2562 & $<0,0001^{*}$ & 0,8116 \\
\hline & Carne gado & 27,5 & 61,2 & 2560 & $<0,0001^{*}$ & 0,5578 \\
\hline & Carne porco & 12,8 & 52,4 & 2560 & $<0,0001 *$ & $<0,0001$ * \\
\hline & Ovos & 11,5 & 49,3 & 2560 & $0,0290 *$ & $<0,0001$ * \\
\hline & Peixe & 4,9 & 30,0 & 2561 & $<0,0001 *$ & $0,0003^{*}$ \\
\hline \multirow{3}{*}{6} & Feijão & 64,6 & 27,9 & 2562 & $<0,0001 *$ & $<0,0001$ * \\
\hline & Ervilha & 3,5 & 19,8 & 2562 & $<0,0001^{*}$ & $<0,0001$ * \\
\hline & Coco & 3,1 & 12,7 & 2551 & $0,0198^{*}$ & 0,9082 \\
\hline \multirow{5}{*}{7} & Nata & 17,7 & 18,3 & 2557 & $<0,0001^{*}$ & $0,0002^{*}$ \\
\hline & Manteiga & 18,5 & 17,1 & 2559 & $<0,0001^{*}$ & $<0,0001$ * \\
\hline & Margarina & 45,5 & 26,8 & 2559 & $<0,0001^{*}$ & 0,3912 \\
\hline & Maionese & 25,8 & 40,0 & 2558 & $0,0005^{\star}$ & $0,0363^{*}$ \\
\hline & Salgados & 21,8 & 50,0 & 2560 & $<0,0001^{*}$ & $0,0254^{*}$ \\
\hline \multirow{5}{*}{8} & Biscoito doce & 21,9 & 42,4 & 2555 & $<0,0001 *$ & 0,8684 \\
\hline & Açúcar & 78,2 & 15,1 & 2558 & $0,0223^{*}$ & $<0,0001$ * \\
\hline & Chocolate/pó & 40,7 & 31,7 & 2562 & $<0,0001 *$ & 0,1484 \\
\hline & Refrigerante & 20,4 & 58,8 & 2558 & 0,1264 & $<0,0001^{*}$ \\
\hline & Bala e doces & 59,5 & 29,0 & 2560 & $0,0085^{*}$ & $<0,0001^{*}$ \\
\hline
\end{tabular}

*Associação estatisticamente significante. 
do limão e do mamão. O consumo de suco natural apresentou freqüência de consumo diário de $36,1 \%$ e semanal de $43,4 \%$, totalizando um consumo semanal de $79,5 \%$ entre os adolescentes, sendo mais freqüente entre as meninas. Quanto ao consumo de frutas de época, não chegam a ser consumidas a pêra (conforme relato de $70,4 \%$ dos escolares), o abacate $(67,3 \%)$, a goiaba $(65,1 \%)$, a manga $(61,3 \%)$ e a uva $(53,3 \%)$, coincidindo serem as mais caras quando adquiridas fora da época de produção. Neste grupo, reuniu-se a freqüência de consumo diário e semanal para identificar os fatores associados.

Associação significante foi encontrada para as frutas consumidas pelos estudantes de classe social mais elevada, tais como: laranja, mamão, maçã, melancia, abacaxi, manga, limão, maracujá e suco natural de frutas. A freqüência de consumo de banana não apresentou associação com a renda. Deste grupo, o consumo de frutas associado ao sexo foi positivo para a laranja, a banana, a melancia, a manga e o limão, sendo essas mais consumidas por meninos. Destaca-se que as meninas apresentaram maior consumo diário de suco natural $(p=0,0496)$.

Para o grupo de leites, o consumo diário de leite integral foi relatado por 45,9\% dos escolares, porém, 31,2\% não o consumiam. Quanto aos outros produtos lácteos, em ordem decrescente de consumo estão o leite desnatado, o queijo, o iogurte e o requeijão. A análise das associações deste grupo compreende a freqüência de consumo diário, cuja associação com a classe econômica foi verificada para todos os alimentos do grupo, que foram mais consumidos por escolares da classe A. O leite desnatado é consumido diariamente por 34,9\% dos escolares da classe A e 19,2\% da classe D+E, porém, a maior associação foi encontrada para o queijo, o qual apresentou consumo de 39,0\% entre os escolares da classe A e 11,3\% da $D+E$.

Em relação ao sexo, as meninas prevalecem entre os escolares que nunca consomem leite e apresentam consumo de leite, iogurte e queijo inferior ao realizado por meninos, sendo esta diferença estatisticamente significante.
Dos alimentos do grupo das carnes e ovos, o consumo semanal mais freqüente foi de carne de gado, seguida da de frango, de porco, ovos e peixe. As vísceras apresentaram baixo consumo semanal (16,3\%) sendo que 69,4\% declararam não consumir este alimento, assim como a rabada (92,0\%).

As associações desse grupo foram realizadas de acordo com o consumo diário e semanal agrupado dos alimentos. Na associação com as classes econômicas, apresentaram significância estatística, entre os menos favorecidos, as carnes de porco e de frango, sendo o consumo diário de frango relatado por $31,4 \%$ dos estudantes das classes D+E e apenas $10,5 \%$ da classe $A$. Já a carne de gado esteve associada aos escolares da classe A. Embora o consumo de rabada, peixe e camarão seja baixo, observou-se que esses alimentos também apresentam maior freqüência de consumo na classe A. Dos escolares da classe A, 56,7\% apresentaram consumo semanal de peixe, e da classe D+E, 18,6\%. Situação oposta foi encontrada entre os que nunca consomem peixe, $16,7 \%$ e 56,9\%, respectivamente. Em relação aos frutos do mar, 96,9\% dos escolares pertencentes à classe D+E e 66,8\% da classe A, não os consumiam. Os ovos são mais consumidos pelos escolares da classe $D+E$, sendo que a associação foi estatisticamente significante.

Quanto ao sexo, a carne de porco era menos consumida pelas meninas, e os meninos apresentaram consumo mais elevado de fígado, ovos, peixe e frutos do mar, sendo estas associações estatisticamente significantes.

Para o grupo das leguminosas e oleaginosas, o feijão era consumido diariamente por $64,6 \%$ dos escolares e no mínimo uma vez por semana por 92,5\%. A ervilha apresentou baixo consumo, pois não era consumida por 59,3\%; o mesmo vale para o coco, uma vez que $64,7 \%$ não o consumiam.

Para a análise desse grupo, utilizou-se a freqüência de consumo diária, cuja associação com a classe econômica mostrou que a ervilha foi mais consumida pela classe $A$, e para a classe $D+E$, o feijão, dos quais a freqüência de consumo foi de 
$41,6 \%$ e $84,6 \%$, respectivamente. Quanto ao sexo, os meninos apresentaram maior consumo de feijão e ervilha.

Do grupo de óleos e gorduras, a margarina foi a mais consumida, seguida da maionese, manteiga e nata. Já o consumo de bacon/toucinho foi baixo: diariamente $4,5 \%$ consumiam este alimento e $20,3 \%$ o faziam semanalmente. Porém, $58,0 \%$ não o consumiam. Quanto à ingestão de salgadinhos, $71,8 \%$ apresentaram consumo semanal, e destes, $21,8 \%$ tinham consumo diário. Para a análise de consumo dos alimentos desse grupo, foi utilizada a freqüência diária, cuja associação com a classe econômica mostrou que o bacon/toucinho era mais consumido pelos mais ricos, enquanto nata, manteiga, margarina, maionese e salgados apresentaram consumo maior entre os escolares das classes $\mathrm{D}+\mathrm{E}$. Ainda de acordo com a classe econômica, o consumo diário de margarina foi encontrado em $60,4 \%$ da classe D+E e 29,8\% da classe A.

A associação com o sexo mostrou que os meninos consomem mais nata, manteiga, maionese e bacon/toucinho e, entre eles, prevalecem os que nunca consomem salgadinhos.

O alimento mais consumido do grupo de açúcares e doces foi o açúcar, seguido da bala/doce e do achocolatado/chocolate. O consumo semanal de refrigerante entre os estudantes foi de $79,2 \%$, e apenas $20,4 \%$ os consumiam diariamente; já o suco artificial foi consumido diariamente por $23,6 \%$ dos escolares. O mel e a gelatina não eram consumidos por 50,1\% e $45,0 \%$ dos adolescentes, respectivamente. 0 sorvete, por sua vez, era consumido semanalmente por $41,0 \%$ dos adolescentes. Destaca-se que para os alimentos deste grupo, as associações referem-se à freqüência diária.

No tocante à classe econômica, entre os alimentos mais consumidos pela classe A estavam o biscoito doce, bolo, mel, chocolate/pó e bombom. Entre os mais consumidos pelas classes $D+E$ destacaram-se o doce de fruta, bala, sorvete e açúcar. Não apresentaram associação com a renda o suco artificial e o refrigerante. As associações referentes ao sexo mostraram que as meninas apresentaram prevalência maior entre os escolares que nunca consomem mel e refrigerantes; entretanto, elas consumiam com maior freqüência açúcar, bombom, bala/doces. Já os meninos apresentaram maior consumo de bolo e refrigerante, todos estatisticamente significativos.

Para o consumo diário de outros produtos alimentares cuja associação estatística foi significante com a classe econômica, encontram-se o catchup ( $p<0,0001)$, a mostarda $(p<0,0001)$ e os produtos dietéticos $(p=0,0023)$ para a classe $A$, enquanto que para a classe $\mathrm{D}+\mathrm{E}$, o café $(p<0,0001)$ e o chá preto $(p=0,0003)$. Os produtos dietéticos eram consumidos diariamente por $10,3 \%$ dos adolescentes, sendo $13,9 \%$ entre os escolares da classe A e 8,2\% entre os da classe $\mathrm{D}+\mathrm{E}$; as meninas apresentaram maior freqüência de consumo diário $(p<0,0001)$. Ainda quanto ao sexo, os meninos eram os maiores consumidores diários de catchup e mostarda $(p<0,0001)$.

O consumo de bebidas alcoólicas foi mais freqüente entre os meninos, sendo a cerveja consumida por $2,5 \%$ dos estudantes diariamente e $21,1 \%$ semanalmente. O vinho era consumido por $2,5 \%$ diariamente e por $13,6 \%$ semanalmente. Quanto às outras bebidas alcoólicas, o consumo semanal foi de $8,6 \%$. Associação significante foi encontrada para o vinho e outras bebidas alcoólicas entre os mais ricos $(p<0,0001)$, e a cerveja era mais consumida pela classe menos favorecida $(p=0,0315)$. Ao verificar o consumo mínimo de uma vez por mês, de todas as bebidas alcoólicas e sua associação com a classe econômica, os resultados mostram que o consumo aumenta com o poder aquisitivo dos escolares $(p<0,0001)$.

\section{S C U S S Ã O}

A freqüência das refeições diárias mostrou que os meninos realizam as principais refeições, ao contrário das meninas, que preferem o lanche da tarde. Essa prática evidencia a necessidade de medidas que incentivem a realização das principais refeições, sendo esse o primeiro passo para uma alimentação adequada. O café da manhã é 
a refeição de maior omissão entre os estudantes de ambos os sexos, de acordo com resultados encontrados em artigos publicados ${ }^{10,16}$. Entretanto, tais achados diferem dos de Garcia et al. ${ }^{17}$, que encontraram maior omissão de desjejum pelas meninas e de Priore $^{18}$, que encontrou o jantar como a refeição menos freqüente entre adolescentes de escolas estaduais, principalmente pelas meninas, cuja associação foi significante. Não há, portanto, um comportamento uniforme para essa questão, variando com a população pesquisada.

Para o grupo dos pães, cereais, raízes e tubérculos, este estudo encontrou associação significante com a renda para todos os alimentos, cujo consumo foi maior na classe de menor renda, mostrando que, apesar do acesso a esses alimentos básicos, uma parcela considerável, pertencente à classe mais favorecida, necessita de estímulo para a prática de uma alimentação saudável, principalmente para as meninas. Pesquisa desenvolvida com adolescentes de 15 a 18 anos mostrou que o consumo diário de arroz ocorre entre os mais pobres, juntamente com o açúcar e o feijão, enquanto o consumo de pão é expressivo para os de classe econômica mais elevada ${ }^{19}$.

Nesse grupo a associação do consumo de pães, cereais, raízes e tubérculos com o sexo, confirmou os resultados obtidos em trabalhos anteriores com adolescentes ${ }^{20}$, sendo que os meninos os consomem com mais freqüência. Dados da Pesquisa sobre Padrões de Vida (PPV) mostraram que a dieta tradicional brasileira, baseada em arroz e feijão, é fator de proteção contra o sobrepeso e a obesidade ${ }^{21}$. O consumo alimentar dos adolescentes da Pesquisa Nutrição e Saúde (PNS), no Rio de Janeiro, encontrou associação entre os meninos com sobrepeso e maior consumo médio de porções do grupo do arroz e feculentos, já as meninas com sobrepeso apresentaram consumo médio menor desses alimentos ${ }^{22}$. Entretanto, estudos mostram que a ingestão de carboidratos na dieta dos adolescentes está abaixo do preconizado ${ }^{18}$, principalmente entre os escolares da rede privada ${ }^{23}$.

No grupo das hortaliças, os resultados deste inquérito estão de acordo com os obtidos em outros estudos, com baixa freqüência de consumo. Muitas variedades de vegetais não fazem parte do hábito alimentar, sendo as meninas as que apresentam consumo mais freqüente ${ }^{16,24}$, assim como os escolares de maior renda 4 . Investigação sobre a rejeição de alimentos mostrou serem as hortaliças as mais rejeitadas pelos adolescentes ${ }^{18}$, porém o tomate e a alface são os vegetais mencionados entre as meninas como de consumo diário $(14,0 \%)$, independentemente do nível econômico ${ }^{19}$. Gama ${ }^{20}$, em estudo com adolescentes, encontrou que os legumes e as frutas estão presentes no hábito alimentar da maioria, porém, $50,0 \%$ deles os consomem abaixo das recomendações.

Quanto à preferência dos adolescentes no presente estudo, a laranja e a banana prevalecem entre as frutas, sendo as de época as que apresentam a menor freqüência de consumo. Em geral, as frutas e os sucos naturais são mais consumidos pelos escolares de maior renda. Outros estudos também demonstram o baixo consumo de frutas entre os adolescentes $3,10,16$, sendo menor entre os meninos ${ }^{16}$ e significantemente maior na classe de maior renda ${ }^{4}$.

Para o grupo de leites e produtos lácteos, esta investigação mostrou que o leite integral não é consumido por um terço dos escolares e, que apenas metade dos entrevistados consome esse alimento diariamente. Tendo em vista a forte associação entre a freqüência de consumo e a classe econômica para todos os alimentos desse grupo, uma vez que a freqüência de consumo foi maior entre os estudantes da classe A, o estudo sugere que os mesmos possuem uma alimentação inadequada. Esse fato é preocupante, principalmente para as meninas e para os escolares de menor renda, dada a importância do cálcio na prevenção da osteoporose, no futuro. Pesquisas confirmam a forte associação com a renda, mostrando que o consumo de leite entre os mais ricos chega a ser três vezes superior ao dos mais pobres $^{25}$, também para meninas adolescentes ${ }^{19}$.

Trabalhos recentes mostram que, entre os adolescentes, os alimentos do grupo de laticínios 
encontram-se entre os de mais baixa freqüência de consumo ${ }^{21,23,25}$, sendo maior entre as meninas, quando comparado com o consumo dos meninos ${ }^{24}$.

Confirma-se, neste inquérito, a preferência pelas carnes de gado e frango e o baixo consumo de peixe e vísceras, mostrando que estes últimos não fazem parte do hábito alimentar dos escolares desta região.

Em estudo desenvolvido com adolescentes de um colégio particular, a carne bovina apresentou a maior freqüência de consumo, seguida do frango e ovos, principalmente fritos, entre os meninos. Esse mesmo estudo mostrou que o peixe esteve entre os alimentos de menor freqüência de consumo ${ }^{24}$. Outra pesquisa desenvolvida com adolescentes do sexo feminino mostrou que fígado, frango e ovos são consumidos somente pelas adolescentes de baixo nível socioeconômico ${ }^{19}$, porém independentemente da renda, outro inquérito evidenciou que o consumo de ovos, peixes e aves, é baixo entre os adolescentes de ambos os sexos ${ }^{16}$, confirmando os achados de que a carne e ovos encontram-se em segundo lugar, entre os alimentos mais rejeitados pelos adolescentes $^{18}$.

As leguminosas não fazem parte do hábito alimentar dos escolares integrantes da pesquisa. Outros trabalhos com escolares dessa faixa etária evidenciam, também, os achados deste estudo, mostrando que o consumo de feijão é baixo e mais freqüente entre os meninos ${ }^{20}$ e entre os mais pobres $^{19}$.

A margarina foi o alimento com maior número de citações no grupo dos óleos e gorduras deste estudo, sendo, em geral, mais consumida por aqueles de menor poder aquisitivo. Os meninos consomem com maior freqüência a manteiga e bacon e as meninas, salgadinhos. Pesquisas mostram que os adolescentes brasileiros apresentam consumo excessivo de gorduras ${ }^{17,18,23}$. Entretanto, Sichieri ${ }^{4}$, ao analisar os dados da PNS, observou que, mesmo não tendo um consumo muito elevado de gorduras, a população apresenta um consumo desproporcional de gordura saturada e de colesterol, sendo esse mais inadequado nas coortes mais jovens.

Gama $^{20}$ encontrou um maior consumo de junk foods e sanduíches consumidos no domicílio entre os meninos, ao contrário do consumo de sanduíches fora do domicílio e salgadinhos, predominante entre as meninas; porém o consumo desses alimentos não caracterizou hábito prejudicial. Artigo publicado recentemente mostrou que 14,0\% dos adolescentes de nível econômico baixo consomem salgadinhos diariamente ${ }^{19}$, sendo que entre adolescentes de classe média o pastel foi o lanche favorito, bem como o suco de frutas com grande quantidade de açúcar ${ }^{26}$. O consumo diário do grupo de açúcares foi confirmado neste estudo, principalmente pelas meninas, sendo o refrigerante o mais popular.

Inquéritos desenvolvidos nas últimas décadas, no Brasil, evidenciam o excessivo consumo de açúcar, que compõe cerca de um quarto do total de carboidratos da dieta dos brasileiros ${ }^{6}$, apresentando ligeira ascensão na proporção de energia proveniente do açúcar e dos refrigerantes ${ }^{3}$. Dados de um estudo multicêntrico mostraram que os refrigerantes foram consumidos em todas as faixas de renda e que a participação no valor energético total da dieta diminuía, conforme aumentava a renda familiar ${ }^{27}$. Pesquisas relatam o alto consumo de refrigerantes no período da adolescência ${ }^{9,17,20}$, sendo o consumo diário de açúcar e refrigerante maior entre os mais pobres ${ }^{19}$ e o de refrigerante entre os meninos ${ }^{20}$.

No presente trabalho investigou-se o consumo de bebidas alcoólicas, o qual não foi expressivo, entretanto apresentou associação estatística com a classe econômica, sendo que seu consumo é mais freqüente entre os escolares mais ricos e do sexo masculino. Recente pesquisa mostrou a baixa freqüência de consumo de bebidas alcoólicas entre os adolescentes. Chama a atenção que $43,8 \%$ dos adolescentes consumiam bebidas alcoólicas, e, destes, $22,9 \%$ o faziam nos finais de semana e o restante $(77,1 \%)$ somente em raras ocasiões ${ }^{18}$. 
A presente pesquisa mostrou, também, associação dos produtos dietéticos com sexo e classe econômica. Este resultado confirma o obtido em inquérito desenvolvido no Rio de Janeiro, no qual a utilização de adoçantes foi maior entre as mulheres, em todas as faixas etárias. Destaca-se que o referido estudo ainda verificou que o consumo de refrigerantes e dos derivados do leite com baixo teor energético, foi mais freqüente entre os indivíduos com sobrepeso ${ }^{4}$. Destaca-se, também, com base em resultado de outra pesquisa entre adolescentes, que as meninas são as maiores consumidoras de produtos com baixo valor energético, sendo os mais freqüentes: refrigerantes, adoçantes, doces, leite e derivados, formulado diet, pães e margarina ${ }^{18}$.

A influência da mídia sobre o consumo alimentar pode ser explicada por Almeida et al. ${ }^{27}$, em recente artigo publicado sobre a propaganda de alimentos veiculados na televisão, o qual mostrou que $57,8 \%$ dos alimentos estão nos grupos da pirâmide alimentar representados por gorduras, óleos, açúcares e doces. Em segundo lugar, com $21,2 \%$, o grupo dos pães, cereais, arroz e massas, seguido do grupo dos laticínios, com $11,7 \%$, e do grupo das carnes com 9,3\%. Observou-se completa ausência de propagandas de frutas e vegetais. A pirâmide construída a partir da freqüência de veiculação de alimentos na TV difere significativamente da pirâmide ideal, havendo uma completa inversão, com quase $60,0 \%$ dos produtos representados pelo grupo de gorduras, óleos e doces e uma conseqüente redução do grupo pão, cereais, arroz e massas, além da ausência de frutas e vegetais.

\section{ONCLUSÃO}

Este estudo confirma a associação da renda familiar com o consumo alimentar dos escolares. O maior consumo de alimentos básicos, como o arroz, o feijão, o açúcar, e de gorduras pelos escolares pertencentes às mais baixas classes de renda, quando comparado com o consumo de outros grupos, evidencia que os mesmos se alimentam predominantemente dos itens da base e do ápice da pirâmide alimentar, sendo esses os mais energéticos.

Quanto ao sexo, este estudo encontrou que os meninos apresentam maior consumo de frutas, feijão e leite do que as meninas, e que realizam as principais refeições, denunciando a necessidade do desenvolvimento de ações educativas que estimulem, principalmente as meninas, a práticas alimentares adequadas, e ainda de estudos posteriores para verificar a adequação da ingestão de nutrientes no grupo estudado.

Uma vez que dados como estes permitem observar características de consumo alimentar de uma população, e que abordagens que levem em conta os alimentos, e não só os nutrientes, são mais facilmente transformados em práticas de saúde, este estudo serve de subsídio para políticas públicas locais, no sentido de estabelecer metas a curto e médio prazo, que proporcionem aos escolares de todas as classes econômicas o acesso a alimentos saudáveis e nutritivos, bem como ações educativas, ainda na infância, visando à formação de hábitos alimentares saudáveis.

Recomenda-se a realização continuada de estudos de consumo alimentar, para melhor conhecer as práticas alimentares, desenvolvendo estratégias para prevenir distúrbios decorrentes do consumo inadequado de nutrientes e energia, considerando-se que adolescentes constituem um grupo de risco, que exige atenção especial para a promoção de hábitos alimentares saudáveis e a garantia de qualidade de vida futura.

\section{COLABORADORES}

M.C. DALLA COSTA concepção do artigo desde o tema até a redação final. L.CORDONI JÚNIOR orientador do projeto e participou na redação final do artigo. T. MATSUO co-orientadora, participou na definição da metodologia, sendo a responsável pela análise esta-tística da pesquisa.

\section{REFER Ê N CIAS}

1. Mondini L. Desnutrição e obesidade no Brasil: relevância epidemiológica e padrões de distri- 
buição intra-familiar em diferentes estratos econômicos e regionais [tese]. São Paulo: Universidade de São Paulo; 1996.

2. Mondini L, Monteiro CA. The stage of nutrition transition in different Brazilian regions. Arch Latinoam Nutr. 1997; 47(2) Suppl. 1:17-21.

3. Monteiro CA, Mondini L, Souza ALM, Popkin BM. Da desnutrição para a obesidade: a transição nutricional no Brasil. In: Monteiro CA, organizador. Velhos e novos males da saúde no Brasil. São Paulo: Hucitec; 2000. p.247-55.

4. Sichieri R. Consumo de alimentos e hábitos relacionados ao consumo. In: Sichieri $R$, organizadora. Epidemiologia da obesidade. Rio de Janeiro: Eduerj; 1998.

5. Organización Mundial de la Salud. Estado físico: uso e interpretación de la antropometría. Ginebra: OMS; 1995. Série de Informes Técnicos, 854.

6. Mondini L, Monteiro CA. Mudanças no padrão de alimentação da população urbana brasileira (1962-1988). Rev Saúde Pública. 1994; 28(6): 433-9.

7. Instituto Brasileiro de Geografia e Estatística. Pesquisa de Orçamento Familiar 2002-2003. Primeiros resultados: Brasil e grandes regiões [acesso em 5 nov 2005]. Disponível em: http:// www.ibge.gov.br

8. Casotti L, Ribeiro A, Santos C, Ribeiro P. Consumo de alimentos e nutrição: dificuldades práticas e teóricas. Cad Debate. 1998; 6:26-39.

9. Frutuoso MFP, Bismarck-Nasr EM, Gambardella AMD. Redução do dispêndio energético e excesso de peso corporal em adolescentes. Rev Nutr. 2003; 16(3):257-63.

10. Vieira VCR, Priore SE, Ribeiro SMR, Franceschini SCC, Almeida LP. Perfil socioeconômico, nutricional e de saúde de adolescentes recém-ingressos em uma universidade pública brasileira. Rev Nutr. 2002; 15(3):273-82.

11. Chaim NA, Teixeira PHR. Caracterização da estrutura de consumo de alimentos na pesquisa "inquérito de consumo alimentar de Campinas". Cad Debate. 1996; 4:47-65.

12. Instituto Brasileiro de Geografia e Estatística. Perfil estatístico de crianças e mães no Brasil. Rio de Janeiro; 1982.

13. Associação Nacional das Empresas de Pesquisa. Critério de classificação econômica Brasil [acesso em 19 fev 2003]. Disponível em: http://www.anep. org.br

14. Sichieri R, Everhart JE. Validity of a Brazilian food frequency questionnaire against dietary recalls and estimated energy intake. Nutr Res. 1998; 18: 1649-59.
15. Philippi ST, Latterza AR, Cruz ATR, Ribeiro LC. Pirâmide alimentar adaptada: guia para escolha dos alimentos. Rev Nutr. 1999; 12(1):65-80.

16. Gambardella AMD, Frutuoso MFP, Franchi C. Prática alimentar de adolescentes. Rev Nutr. 1999; 12(1): 55-63.

17. Garcia GCB, Gambardella AMD, Frutuoso MFP. Estado nutricional e consumo alimentar de adolescentes de um centro de juventude da cidade de São Paulo. Rev Nutr. 2003; 16(1):41-50.

18. Priore SE. Composição corporal e hábitos alimentares de adolescentes: uma contribuição à interpretação de indicadores do estado nutricional [tese]. São Paulo: Universidade Federal de São Paulo; 1998.

19. Oliveira MNG, Soares EA. Comparação do perfil dietético de adolescentes femininas e níveis socioeconômicos diferenciados. Nutr Brasil. 2002; 1(2):68-76.

20. Gama CM. Hábito alimentar e condição nutricional de adolescentes de bom nível socioeconômico em São Paulo [tese]. São Paulo: Universidade Federal de São Paulo; 1997.

21. Sichieri R, Castro JFG, Moura AS. Fatores associados ao padrão de consumo alimentar da população brasileira urbana. Cad Saúde Pública. 2003; 19(1):47-53.

22. Andrade RG, Pereira RA, Sichieri R. Consumo alimentar de adolescentes com e sem sobrepeso do Município do Rio de Janeiro. Cad Saúde Pública. 2003; 19(5):1485-95.

23. Kazapi IM, Di Pietro PF, Avancini SRP, Freitas SFT, Tramonte VLCG. Consumo de energia e macronutrientes por adolescentes de escolas públicas e privadas. Rev Nutr. 2001; 14:27-33.

24. Carvalho CMRG, Nogueira AMT, Teles JBM, Paz SMR, Sousa RML. Consumo alimentar de adolescentes matriculados em um colégio particular de Teresina, Piauí, Brasil. Rev Nutr. 2001; 14(2):85-93.

25. Instituto Brasileiro de Geografia e Estatística. Pesquisa de Orçamentos Familiares - 1995/1996. Rio de Janeiro; 1998. v.2.

26. Doyle El, Feldman RHL. Factors affecting nutrition behavior among middle-class adolescents in urban area of Northern region of Brazil. Rev Saúde Pública. 1997; 31(4):342-50.

27. Almeida SS, Nascimento PCBD, Quaioti TCB. Quantidade e qualidade de produtos alimentícios anunciados na televisão brasileira. Rev Saúde Pública. 2002; 36(3):353-5.

Recebido em: 30/11/2005

Versão final reapresentada em: 13/4/2007 Aprovado em: 10/7/2007 
